\title{
PENDAPATAN USAHA DAN PERSEDIAAN BAHAN BAKU INDUSTRI BAWANG GORENG (Studi Kasus Industri Bawang Goreng “Uda Saprudin”)
}

\author{
Herlena Bidi Astuti*, Yesmawati*, Linda Harta*, Reswita**
}

\begin{abstract}
ABSTRAK
Pengolahan bawang merah menjadi bawang goreng merupakan salah satu usaha agroindustry dengan bahan baku pokok bawang merah. Industri rumah tangga bawang goreng merupakan hilirisasi dari komoditas pertanian dengan memberikan nilai tambah dari bahan baku bawang merah, dalam proses produksi pelaku industri harus melakukan manajemen yang baik akan persediaan bahan baku untuk menjamin ketersediaan produk. Tujuan dari penelitian ini adalah untuk mengetahui pendapatan usaha bawang goreng dan mengetahui manjemen persediaan bahan baku pada industry bawang goreng "Uda Saprudin" di Kota Bengkulu. Metode yang digunakan dalam penelitian ini adalah penghitungan pendapatan, $R / C$ ratio, dan manjemen persediaan bahan baku dengan menggunakan pendekatan EOQ, Safety Stock, Reorder Point, lead time dan Total inventory cost. Penelitian ini adalah study kasus dilakukan pada February 2019 dengan data yang digunakan adalah data satu tahun terakhir (2018). Dari hasil penelitian didapatkan hasil nilai $R / C$ sebesar 1,36 dan pada manjemen persediaan bahan baku diketahui nilai EOQ : $6.546 \mathrm{Kg}$, nilai Reorder Point : $6.329 \mathrm{Kg} /$ Bulan, lead time : 0,5 bulan dan Total inventory cost : $R$ p. 163.676 .047 pertahun.
\end{abstract}

Kata Kunci : Pendapatan, Usaha, Manajemen, Bahan Baku, Bawang Merah

\begin{abstract}
Processing shallots into fried onions is one of the agro-industry businesses with the main raw material of shallots. The fried onion home industry is a downstreaming of agricultural commodities by providing added value from the raw materials of shallots, in the process of production competition the industry must conduct management that will produce raw materials to ensure obtaining products. The purpose of this study was to determine the operating income of fried onions and determine the management of raw materials in the "Uda Saprudin" fried onion industry in Bengkulu City. The method used in this study is the calculation of income, $R$ / $C$ ratio, and management of raw materials using EOQ, Safety Stock, Reorder Points, lead time and total inventory costs. This research is a case study conducted in February 2019 with the data used is the data of the past year (2018). From the research results obtained $R / C$ value of 1.36 and the management of raw material requirements recognized EOQ value: $6.546 \mathrm{Kg}$, Reorder Point value: $6.329 \mathrm{Kg} /$ Month, lead time: 0.5 months and Total inventory costs: Rp. 163,676,047 per year.
\end{abstract}

Keywords: revenue, business, management, raw materials, shallots

PENDAHULUAN
Indonesia sampai hari ini masih dikenal sebagai negara agraris dimana 
sebagian besar penduduk Indonesia berprofesi sebagai petani, oleh sebab itu pemerintah cukup memberikan perhatian dibidang pertanian. Sebagai negara yang masih menjadikan pertanian tumpuan perekonomian (Sukmawan dkk. 2015; Maulana dkk.2017 ) Indonesia banyak melakukan perencanaan dibidang pertanian dan masih menjadi perhatian serius hal ini terlihat dari Rencana Pembangunan Jangka Menengah Nasional (RPJMN) RI yang memuat salah satu arah kebijakan strategis untuk peningkatan kesejahteraan masyarakat adalah dengan pengembangan sektor pertanian (BPPN,2015) salah satu bagian penting dari peningkatan pendapatan petani adalah dengan mengolah hasil pertanian yang bersifat cepat rusak menjadi produk yang memiliki nilai tambah atau bias dikenal dengan istilah agroindustri.

Agroindustri adalah kegiatan yang memanfaatkan hasil pertanian sebagai bahan baku, merancang dan menyediakan peralatan serta jasa untuk kegiatan tersebut. secara eksplisit pengertian Agroindusri pertama kali diungkapkan oleh Austin (1981) yaitu perusahaan yang memproses bahan nabati (yang berasal dari tanaman) atau hewani (yang berasal dari hewan). Proses yang digunakan mencakup pengubahan dan pengawetan melalui perlakuan fisik atau kimiawi, penyimpanan, pengemasan dan distribusi. Produk Agroindustri dapat merupakan produk akhir yang siap dikonsumsi ataupun sebagai produk bahan baku industri lainnya (Badar dkk, 2012., Kingdangen.2014 ). Pengertian lainnya agroindustri seperti dinyatakan oleh Goldberg dalam Mangun Widjaja dan Sailah, (2009).,Udayana (2011) agroindustri merupakan bagian dari kompleks industri pertanian sejak produksi bahan pertanian primer, industri pengolahan atau transformasi sampai penggunaannya oleh konsumen.

Pengolahan bawang merah menjadi bawang goreng merupakan salah satu usaha agroindustry dimana Bawang merah merupakan salah satu produk komoditas hortikultura komersial yang dikategorikan tanaman akar (Kanna,2016) yang banyak dikonsumsi dan dibutuhkan oleh semua kalangan dan banyak sector mulai dari rumah tangga hingga perusahaan pengolahan makanan. Di Provinsi Bengkulu produksi bawang merah belum bisa memenuhi semua permintaan lokal akan komoditas ini pada tahun 2015 jumlah produksi bawang merah di provinsi Bengkulu 4.450 kwintal dan cenderung menurun dibanding tahun sebelumnya (2014) sebanyak 4.604 kwintal. (BPS.2018). 
Pengembangan sector pertanian di Provinsi Bengkulu masih harus terus ditingkatkan mengingat sektor ini masih bisa menyerap tenaga kerja. Di Provinsi Bengkulu dari 1.033,40 juta jiwa angkatan kerja ada 27,9 ribu jiwa berstatus sebagai pengangguran (BPS, 2018). Selain penyerapan tenaga kerja dibidang pertanian meningkatkan dan mengembangkan sektor industry rumah tangga sebagai hilirisasi produk pertanian dapat menjadi solusi untuk mengatasi pengangguran di Provinsi Bengkulu. Salah satu produksi rumah tangga yang berbasis bahan baku dari komoditas pertanian adalah industry bawang goreng. Dalam industry bawang goreng memerlukan pasokan akan bahan baku yang berkelanjutan untuk menjamin terus berlangsung proses produksi serta menjamin ketersediaan produk di pasaran oleh sebab itu diperlukan kemampuan akan manajemen persediaan bahan baku dari suatu proses produksi.

Industri rumah tangga bawang goreng merupakan hilirisasi dari komoditas pertanian dengan memberikan nilai tambah dari bahan baku bawang merah, dalam proses produksi pelaku industri harus melakukan manajemen yang baik akan persediaan bahan baku untuk menjamin ketersediaan produk oleh sebab itu dirumuskan beberapa permasalahan dalam manjemen persediaan bahan baku industry adalah jumlah pembelian ekonomis, persediaan pengamanan, nilai reorder dan nilai total biaya persediaan baku pada industry rumah tangga bawang goreng. Berdasarkan masalah ini maka tujuan dari penelitian ini adalah untuk mengetahui pendapatan usaha, jumlah pembelian ekonomis, nilai reorder atau pemesanan kembali dan mengetahui nilai total biaya persediaan bahan baku pada industry rumah tangga bawang goreng.

\section{METODEWaktu Dan Tempat}

Penelitian dilakukan di Kota Bengkulu pada bulan Maret 2019 pada industry rumah tangga "Uda Saprudin" Kota Bengkulu. Responden ditentukan secara purposive pada industry rumah tangga bawang goreng "Uda Saprudin" yang berlokasi di Kelurahan Rawa Makmur Kota Bengkulu.

\section{Pengumpulan Data}

Data primer dikumpulkan dengan cara survey dan wawancara kepada pihak industry untuk penghitungan persediaan bahan baku bawang merah selama 1 tahun sedangkan data sekunder dikumpulkan dengan cara desk study. 


\section{Analisis Pendapatan Usaha}

Mengetahui keuntungan suatu usaha diperlukan penghitungan yang cermat. Pendapatan dapat diketahui dari penerimaan setelah dikurangi dengan semua pengeluaran selama proses produksi (Normansyah dkk.2014). Penerimaan merupakan pendapatan kotor (income approach) merupakan jumlah produk yang dihasilkan pada suatu periode produksi dikalikan dengan harga per satuan produk tersebut sedangkan pendapatan merupakan selisih dari penerimaan dengan biaya yang dikeluarkan selama proses produksi yang di rumuskan sebagai berikut (Gupito dkk. 2014)

$$
\begin{aligned}
& \Pi=\text { Pendapatan } \mathrm{Q}=\text { Total } \\
& \text { product }
\end{aligned}
$$

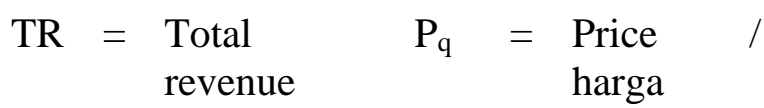

$$
\begin{aligned}
& \mathrm{TC}=\text { Total cost } \quad \mathrm{FC}=\begin{array}{l}
\text { produk } \mathrm{q} \\
\text { Fixed cost }
\end{array} \\
& \mathrm{VC}=\text { Variable } \\
& \text { cost }
\end{aligned}
$$

Keterangan :

$$
\begin{array}{rll}
\mathrm{TR} & \mathrm{Q} \times \mathrm{P}_{\mathrm{q}} \\
\mathrm{TC} & : & \mathrm{FC}+\mathrm{VC} \\
\Pi & : & \mathrm{TR}-\mathrm{TC}
\end{array}
$$

\section{Persediaan Bahan Baku}

Persediaan bahan baku didalam sebuah proses produksi produk dapat diartikan sebagai suatu usaha untuk menyediakan bahan untuk untuk proses produksi dan datangkan satu persatu dalam satuan jumlah tertentu. Untuk menghindari kekurangan bahan baku, home industry sama seperti perusaaan pada umumnya melakukan penyediaan bahan baku dalam jumlah yang banyak. Tetapi persediaan bahan baku dalam jumlah besar tersebut akan mengakibatkan terjadinya biaya persediaan bahan yang semakin besar pula. Besarnya biaya persediaan ini berarti akan mengurangi keuntungan perusahaan. Disamping itu, resiko kerusakan bahan juga akan bertambah besar apabila persediaan bahan bakunya besar.

$$
\text { Industry pengolahan sangat }
$$
tergantung dengan persediaan bahan demikian juga dengan industry rumah tangga bawang merah. Bawang merah sebagai komoditas pertanian memiliki sifat dengan risiko kerusakan produk yang tinggi serta dalam penyediaan stock dipasar sangat dipengaruhi oleh lingkungan tumbuh dan kemampuan varietas bawang merah beradaptasi dengan lingkungan sehingga dapat menghasilkan produktivitas yang tinggi (rusli dan Asaad, 2016). Metode yang digunakan untuk menghitung dan menganalisis persediaan bahan baku menggunakan metode Economic Order 
Quantity (EOQ), Safety Stock, Reorder Poin dan Total Inventory cost (TIC) menurut Nissa dan siregar (2017).

\section{Economic Order Quantity (EOQ)}

EOQ merupakan persamaan untuk menentukan kualitas pesanan persediaan yang meminimumkan biaya langsung penyimpanan persediaan dan biaya pemesanan persediaan. Persamaan EOQ dapat dirumuskan sebagai berikut :

$$
\mathrm{EOQ}=\sqrt{\frac{2 D S}{H}}
$$

Keterangan :

$\mathrm{EOQ}=$ kuantitas pembelian ekonomis bahan baku $(\mathrm{Kg})$

$\mathrm{D}=$ Kebutuhan penggunaan bahan baku dalam satu satuan waktu $(\mathrm{Kg})$

$$
\mathrm{S} \text { = Biaya Pemesanan bahan }
$$
baku tiap kali pesan $(\mathrm{Rp})$

$\mathrm{H}$ = Biaya Penyimpanan (Rp)

\section{Pemesanan Kembali (Reorder Point)}

Pemesanan kembali merupakan pengalian antara waktu tunggu dengan penggunaan bahan baku rata-rata perhari atau dapat dibuat dalam persamaan sebagai berikut :

$\mathrm{ROP}=\mathrm{A} \times$ Lead time

Keterangan :
A = penggunaan bahan baku rata-rata

$\mathrm{ROP}=$ reorder point

Lead time $=$ waktu tunggu

\section{Total biaya Persediaan Bahan Baku}

(Total Inventory cost)

Total biaya persediaan bahan baku

(TIC) dapat digambarkan dengan persamaan berikut :

$$
\mathrm{TIC}=\mathrm{D} / \mathrm{Q}(\mathrm{S})+\mathrm{Q} / 2(\mathrm{H})
$$

Keterangan :

$\mathrm{TIC}=$ total biaya persediaan

ekonomis bahan baku

$\mathrm{D}=$ Jumlah pembelian bahan baku perbulan $(\mathrm{Kg})$

$$
\mathrm{Q}=\text { Jumlah pembelian }
$$

ekonomis bahan baku perbulan $(\mathrm{Kg})$

$$
\mathrm{S}=\text { biaya pemesanan bahan }
$$

baku permesanan $(\mathrm{Rp})$

$$
\mathrm{H}=\text { biaya penyimpanan bahan }
$$

baku per Kg (Rp)

\section{HASIL DAN PEMBAHASAN}

\section{Pendapatan Usaha}

Memperoleh pendapatan yang memadai merupakan tujuan dari suatu usaha. Berbagai masalah dalam industri rumah tangga adalah Sebagai negara yang sedang berkembang Indonesia masih mengandalkan sektor agraris dan 
teknologinya banyak yang masih berasal dari negara maju. Meningkatkan pendapatan masyarakata dapat dilakukan dengan mendorong usaha pascapanen dari produk pertanian. Produk pertanian yang mudah rusak dan memiliki harga yang fluktuatif memerlukan pengolahan lebih lanjut untuk mendapatkan nilai tambah atau harga yang lebih. Menghasilkan nilai tambah memerlukan biaya sebagai komponen yang mengurangi suatu tujuan, sedangkan manfaat adalah segala sesuatu yang membantu suatu tujuan.(Harini dkk. 2014) Tabel 1. Biaya dan pendapatan usaha dari usaha bawang goreng "uda Saprudin"

\begin{tabular}{|c|c|c|c|}
\hline No & Uraian & \multirow[t]{2}{*}{ Jumlah (Rp) } & \\
\hline 1 & Biaya & & \\
\hline & a. Bawang merah & 8.100 .000 & \\
\hline & b. Minyak goreng & 140.000 & \\
\hline & c. Tepung beras & 140.000 & \\
\hline & d. Kayu bakar & 21.429 & \\
\hline & e. Plastic & 16.000 & \\
\hline & f. Tenaga kerja & 800.000 & \\
\hline & g. Biaya penyusutan alat & 106.000 & \\
\hline & Jumlah biaya & & 9.323 .429 \\
\hline 2 & Produksi : $150 \mathrm{~kg}$ & & \\
\hline 3 & Harga & 85.000 & \\
\hline 2. & Penerimaa & & 12.750 .000 \\
\hline 3 & Pendapatan & & 3.426 .571 \\
\hline 4 & $\mathrm{R} / \mathrm{C}$ & & 1,36 \\
\hline
\end{tabular}

Sumber : Data Primer Diolah 2019

Biaya dan penerimaan dari usaha bawang goreng "Uda Saprudin" dapat dilihat pada tabel 1. Biaya yang dihitung adalah untuk satu kali produksi dengan bahan baku $450 \mathrm{~kg}$ bawang merah dengan hasil produksi $150 \mathrm{~kg}$ bawang goreng. Biaya tertinggi pada industri pengolahan bawang goreng "Uda Saprudin" adalah pada pembelian bahan baku bawang merah yaitu
$86,87 \%$ dari total biaya yang dikeluarkan. Selain bahan baku biaya tenaga kerja cukup tinggi daripada biaya pembelian bahan tambahan industri lainnya. Industri rumah tangga umumnya sangat tergantung dengan tenaga kerja dalam keluaga dan kekurangan tenaga kerja akan berpengaruh pada jalannya proses produksi (Kario, 2016 dan Setiaji dan Khoirudin. 2018 ) 
Usaha bawang goreng ini semua berasal dari Sumatera Barat tepatnya menghasilkan keuntungan Rp. 3.426.571 / Kabupaten Solok dan sebagai pembeli bahan hari untuk satu kali produksi dengan nilai R/C 1,36. Pendapatan usaha sangat tergantung dengan harga-harga dari semua bahan yang akan digunakan dalam proses produksi. Menjadi masalah tersendiri bagi usaha agroindustry adalah sifat bahan baku yang tidak tahan lama dan harga bahan baku yang fluktuatif.

\section{Analisis Persediaan Bahan Baku}

Permintaan akan bawang goreng diakui oleh pemilik industri beberapa tahun terakhir tidak banyak mengalami peningkatan namun terus ada dan stabil sehingga untuk memenuhi permintaan industry "Uda Saprudin" harus selalu menyediakan bahan baku untuk tetap berproduksi dan memenuhi permintaan konsumen. Persediaan bahan baku pada industry bawang goreng "Uda Saprudin"

baku yang yang sudah dikenal maka pihak Uda saprudin sudah memiliki beberapa pedagang pengumpul yang membeli bawang merah dari petani. Bawang merah merupakan bahan baku utama dalam industry bawang goreng dengan harga pembelian rata-rata Rp. 18.000 per Kilogram.

Jumlah Pembelian Ekonomis (EOQ), merupakan penghitungan untuk mengetahui jumlah bahan baku setiap kali pembelian akan menimbulkan biaya terendah tetapi tidak akan menimbulkan kerugian dan kekurangan bahan baku pada usaha industri bawang goreng “Uda Saprudin”nilai EOQ pada "Uda Saprudin adalah 6.546 kg untuk setiap kali pemesanan. Pada industri ini pemesanan dilakukan dua kali dalam satu bulan dengan biaya setiap kali pemesanan adalah Rp. 7.020.000.

Tabel 2. Kebutuhan dan penggunaan bahan baku Januari - Desember 2018 pada "Uda Saprudin". 


\begin{tabular}{lll}
\hline No & Bulan & Kebutuhan $(\mathbf{K g})$ \\
\hline 1 & Januari & 12.600 \\
2 & Februari & 12.600 \\
3 & Maret & 12.600 \\
4 & April & 12.600 \\
5 & Mei & 12.600 \\
6 & Juni & 14.000 \\
7 & Juli & 12.600 \\
8 & Agustus & 12.600 \\
9 & September & 12.600 \\
10 & Oktober & 12.600 \\
11 & November & 12.600 \\
12 & Desember & 12.600 \\
\hline & Jumlah & 152.600 \\
\hline
\end{tabular}

Sumber : Data primer diolah 2019

Jumlah bahan baku tertinggi yang digunakan untuk satu kali produksi adalah $500 \mathrm{~kg}$ dan jumlah rata-rata penggunaan bahan baku setiap kali produksi adalah 450 kg. Berdasarkan tabel 2 dapat diketahui bahwa nilai ROP dari industry bawang goreng "Uda Saprudin adalah sebesar 6.329 $\mathrm{kg}$ per bulan dengan lead time 0,5 bulan dan penggunaan bahan baku rata-rata perbulan adalah sebesar $12.717 \mathrm{~kg}$. Sifat produk bahan baku yang mudah rusak membuat pihak industry bawang goreng tidak dapat menyimpan bahan baku dalam jangka waktu yang lama. (Sappemasse dan Howara, 2017)

Total biaya persediaan bahan baku atau Total inventory cost (TIC) digunakan untuk mengetahui besarnya total biaya yang digunakan dalam melakukan persediaan bahan baku untuk setiap bulan/tahun. Pada usaha industry bawang goreng "Uda
Saprudin" besar nilai TIC adalah Rp. 163.676.047 per tahun. Artinya untuk menjaga keberlanjutan usaha dan kesediaan bahan baku industry bawang goreng "Uda Saprudin" harus menyediakan biaya Rp. 163.676.047 pertahun.

\section{KESIMPULAN}

1. Pendapatan usaha bawang goreng Uda Saprudin adalah Rp. 3.426.571 per satu kali produksi dengan nilai $\mathrm{R} / \mathrm{C}$ adalah 1,36

2. Industri bawang goreng "Uda Saprudin" memiliki jumlah pembelian ekonomis (EOQ) sebesar $6.546 \mathrm{Kg}$ dengan Nilai ROP sebesar $6.359 \mathrm{Kg}$ serta TIC sebesar Rp. 163.676.047 pertahun.

\section{DAFTAR PUSTAKA}


Austin, J.E. 1981. Agroindustrial Project Analysis. The John Hopkins University Press. London

BPPN. 2015. Rencana Pembangunan Jangka Menengah Nasional Tahun 20152019 Republik Indonesia. Kementerian Perencanaan Pembanguna Nasional RI.

BPS. 2018. Indikator Kesejahteraan Rakyat tahun 2017. Badan Pusat Statistik Provinsi Bengkulu.

Badar, AK., Anam, M., dan Assagofi H. J., 2013. Agroindustri di Indonesia. Makalah Sekolah Tinggi Agama Islam Negeri Kudus.

Gupito RW, Irham, Lestari, Rahayu Waluyati. 2014. Analisis Faktorfaktor Yang Mempengaruhi Pendapatan Usahatani Sorgum Di Kabupaten Gunung Kidul. Jurnal Agro Ekonomi. Volume 24. No 1. Halaman 66-75

Harini Rika, Nurdin MH dan Aprilia Lucky. 2014.Tinjauan Spasial Analisis Ekonomi Usahatani Pada Lahan Pertanian Terkonversi Di Kabupaten Sleman. Prosiding Pertemuan Imiah Tahunan (PIT) Ikatan Geograf Indonesia. Halaman 475-483

Kanna,V.N dan P Reddy.2016. Agribusiness Analysis of Onion in Ethiopia. IAARD Journals. Volume 2 . Nomor 1. Halaman 113-123

Kario NH. 2016. Dampak Kelangkaan Tenaga Kerja Pengolahan Kelapa Terhadap Pendapatan Petani Dan Tenaga Kerja di Minahasa Tenggara. Buletin Palma. Volume 17. Nomor 1. Halaman 79-87.

Kingdangen, JG., 2014. Prospek Pengembangan Agroindustri Pangan dalam Meningkakan Pendapatan Masyarakat Tani di di Kabupaten
Minahasa Tenggara. Seminar Regional Inovasi Pertanian, Mendukung Program Pembangunan Provinsi Sulawesi Utara. Balai Pengkajian Teknologi (BPTP) Sulawesi Utara.

Mangunwidjaja, D., dan I. Sailah, 2009. Pen gantar Teknologi Pertanian. Penebar Swadaya. Jakarta.

Maulana M, Simatupang $\mathrm{P}$ dan Reni Kustiari. 2017. Outlook Indikator Makro Global Dan Sektor Pertanian 2016-2019. Jurnal Analisis Kebijakan Pertanian (Agricultural Policy Analysis). Volume 15.Nomor 2. Halaman 151-165.

Nissa K dan Siregar MT. 2017. Analisis Pengendalain Persediaan Bahan Baku Kain Kemeja Poloshirt Menggunakan Metode Economic Order Quantity (EOQ) di PT Bina Busana Internusa. International Journal of Social Science and Business. Volume 1. Nomor 4. Halaman 271-279.

Normansyah D, Rochaeni S, Humaerah AD. 2014. Analisis Pendapatan Usahatani Sayuran Di Kelompok Tani Jaya, Desa Ciaruteun Ilir, Kecamatan Cibungbulang, Kabupaten Bogor. Jurnal Agribisnis. Volume 8. No.1. Halaman 29-44

Sappemase dan Howara.2017. Analisis Persediaan Bahan Baku Pada Industri Bawang Goreng "Mahkota" di Kota Palu. E-jurnal. Agrotekbis. Volume 5. Nomor 6. Halaman 714719

Sukmawan Yan, Sudrajat, dan Sugiyanta. 2015. Peranan Pupuk Organik dan NPK Majemuk terhadap Pertumbuhan Kelapa Sawit TBM 1 di Lahan Marginal. Jurnal J.Agron. Indonesia. Volume 43 No 3. Halaman 242 - 249. 
Setiaji WB dan Khoirudin Rifki. 2018. Analisis Determinan Pendapatan Usaha Industri Mikro Kecil Tahu Di Trunan,Tidar Selatan,Magelang Selatan Kota Magelang. Jurnal Dinamika Ekonomi Pembangunan
(JDEP). Volume 1. No.3. Halaman $1-14$

Udayana, GB., 2011. Peran Agroindustr $i$ dalam Pembangunan Pertanian. Singhadwala, Edisi 44, Februari 2011.

*BPTP Balitbangtan Bengkulu, J1 Irian KM 6,5 Kota Bengkulu

** Dosen di Jurusan Sosial Ekonomi Fakultas Pertanian Universitas Bengkulu

(Email : lenabidi@gmail.com) 